\title{
THERMAL DIAGNOSTIC SYSTEMS AND THEIR APPLICATION FOR ANALYSIS OF TRANSFORMER WINDING
}

\section{Milan SEBOK, Matej KUCERA, Daniel KORENCIAK, Miroslav GUTTEN}

Department of Measurement and Application Electrical Engineering, Faculty of Electrical Engineering and Information Technology, University of Žilina, Univerzitna 1, 01026 Zilina, Slovakia, Email: milan.sebok@fel.uniza.sk, matej.kucera@fel.uniza.sk, daniel.korenciak@fel.uniza.sk, miroslav.gutten@fel.uniza.sk

\begin{abstract}
This paper is focused application of chosen thermal non-contact and contact methods for quality diagnostics of the transformer windings. In the first part of the paper it examines basic principles and application of non-contact temperature measurement on power transformers by thermovision. The second part is focused on analysis of thermal processes in distribution transformer. In the finally, it is examined experimental measurement on laboratory transformer with task to detect mechanical strength and subsequently short-circuit resistance of its winding. By means of the experimental measurements and following analysis it was showed the practical thermovision and contact thermal measurement by optical detectors for diagnostics of power oil transformers in field mechanical strength of winding material.
\end{abstract}

Keywords: thermovision, emissivity, radiation, temperature, diagnostics, transformer

\section{INTRODUCTION}

Basic diagnostics for a non-destructive measurement of electrical devices using thermovision, is the opportunity to record infrared radiation to the form of real thermal pictures of measured objects, and on the basis of overheating of certain surround, for a detection of a fault (defect).

With non-contact measurement it is possible to verify the temperature distribution on the surface of measured objects using sensitivity measuring of a few Kelvin (or ${ }^{\circ} \mathrm{C}$ ) decimal [1].

Infrared radiation is generated as a result of various physical processes that take place in the object of radiation; vibration in crystal lattice, moving atoms, molecules and transition of electrons from one energy level to another. The basic source of infrared radiation is elevated temperature of the radiation source.

Radiation of thermal sources acts like (in respect of ambient conditions), like visual light. For thermovision is important to identify materials used for elements of visualization systems, that size of values which are derived from the wavelength of material radiation, and also sensitivity of sensors for recording the signal.

Precision of thermal measurement for thermovision diagnostics is impacted by following factors:

- incorrect determination of emissivity - radiation coefficient of measured object $\varepsilon(\lambda, T)$,

- low current load of measured electric equipment, because current load has a relevant role for assessment of measuring warming,
- influence of other hot objects close to measured objects and inaccurate determination of surrounding temperature can cause both changes of emission coefficient,

- incorrectly interpretation of measured values of warming,

- various surfaces (the surface may be chromatic, oxidized surfaces and peeled paint on materials) may cause wrong evaluation of results.

For diagnostics of infrared radiation by thermovision the inside transfer and distribution of electric power, it is need to take into account many relevant factors affecting the measurement accuracy [2].

Fundamental for a non-destructive diagnostics of electrical devices using thermovision systems, is the ability to record and to work infrared radiation (thermal radiation) to the form of real thermal images Fig. 1, of measured objects, and on the basis of overheating of certain parts diagnosed objects, to detect a fault (defect).

The research analysis show that the method based on recognition of thermal images may be profitable for technical engineers [3].

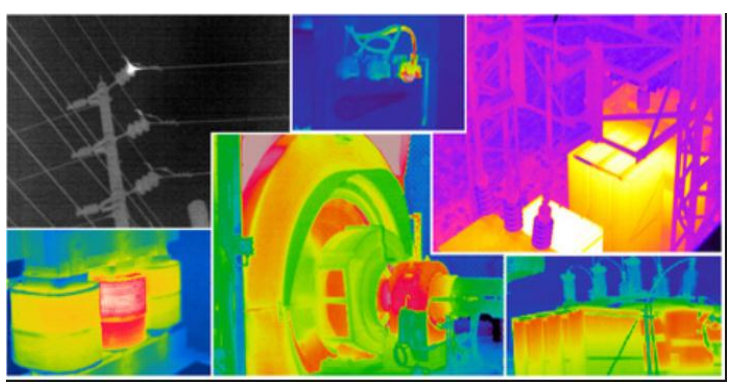

Fig. 1. Thermogram of electrical equipments 


\section{THE THEORY OF INFRARED RADIATION}

The surface of the measured object in a state of thermodynamic equilibrium emits electromagnetic radiation and the radiated power depends on the thermodynamic temperature and properties of the object surface. Radiation power (intensity) $H(\lambda, T)$ is the only parameter that is measured by infrared receiver and is a function for emission coefficient $\varepsilon(\lambda, T)$ and temperature $T$ of radiation source [4].

$$
H(\lambda, T)=\varepsilon \sigma T^{4}
$$

This uncertainty (the value of one parameter is subject of another parameter) is one of the problems of measuring the infrared radiation. Emission coefficient too depends on the direction from which is the radiation recorded, on the temperature and also on the surface of material.

Heating is defined by the relationship $\alpha / \varepsilon$, where $\alpha$ is the absorption coefficient of energy and $\varepsilon$ is the emission coefficient (emissivity) of the measured body [5].

In Fig. 2 is dependence of spectral density intensity of radiation to wavelength.

Ratio of intensity radiation of actual body and ideal black body at the same temperature is defined by spectral emissivity coefficient: [6]

$$
\varepsilon_{\lambda}(\lambda, T)=\frac{H_{\lambda}(\lambda, T)}{H_{0 \lambda}(\lambda, T)}
$$

In Fig. 2 is dependence of spectral density intensity of radiation to wavelength.

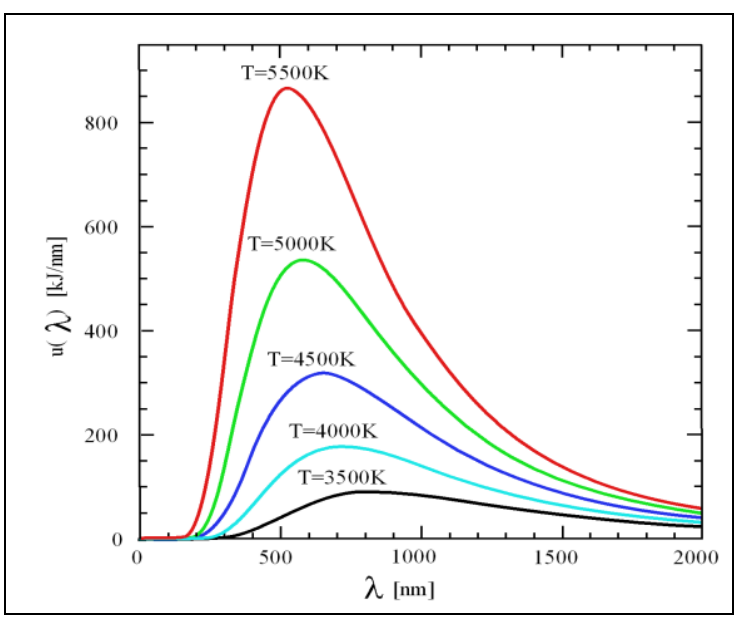

Fig. 2. Dependence of spectral density - intensity of radiation to wavelength

Coefficient of spectral emissivity is equal to the spectral absorption coefficient. The research on issues of radiation of solid bodies is based on knowledge of absolute black body; an object which is able to fully absorb the full spectrum of radiated energy. By Kirchhoff's law the black body is an ideal emitter. Plank defines the spectrum of black body radiation.

$$
\frac{d H(\lambda, T)}{d \lambda}=\frac{2 \pi h c^{2} \lambda^{-5}}{e^{\frac{h c}{\lambda k T}}-1}
$$

where

$d H(\lambda, T)$ - spectral radiant flux density surface, i.e. radiated power, which is emitted by a unit surface of the black body in an interval of wave length,

$h=6.625 .10-34 \mathrm{~J} . \mathrm{s}$ - Planck constant,

$k=1,38054.10^{-23}$ - Boltzmann constant,

$c$ - speed of light,

$T$ - absolute temperature of black body in ${ }^{\circ} \mathrm{K}$ [7].

Spectral radiant flux density of black body surface depends on the length of the wave and temperature. Plank's law is a function of spectral distribution of values

$$
\frac{d H(\lambda, T)}{d \lambda}=f_{T}(\lambda)
$$

Real objects generally do not behave as black bodies. No-black bodies absorb only a part of $\alpha(\lambda) \Phi$ (incident radiation), part of the reflected radiation $\varepsilon(\lambda) \Phi$ and part $\tau(\lambda) \Phi$ is transient radiation. Coefficients $\alpha(\lambda), \varepsilon(\lambda), \tau(\lambda)$ are selective and depend on the wavelength.

If the system is in thermodynamic equilibrium (Fig. 3), under the law of conservation of energy reflected and transient energy is equal to the energy absorbed.

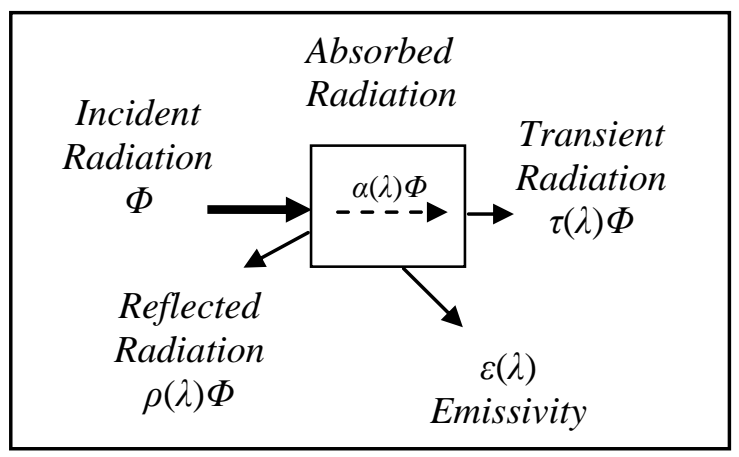

Fig. 3. Distribution of the incident radiation

Difficulties arise when the body is surrounded by other objects, which have high temperature and these temperatures are higher than the examined object [9].

In this case, its own radiation depends on the $T_{0}$ and $\varepsilon_{0}$ affected by reflected radiation error caused by parasitic (surrounding) objects with a temperature $T_{\mathrm{e}}$ and emissivity $\varepsilon_{\mathrm{e}}$. (Fig. 4). If the reflection coefficient is measured as $\rho_{\mathrm{e}}$ - radiation error, then the part characterizing the error is proportional to $T_{\mathrm{e}}, \varepsilon_{\mathrm{e}}$ and $\rho_{\mathrm{e}}, T_{\mathrm{e}}$. 


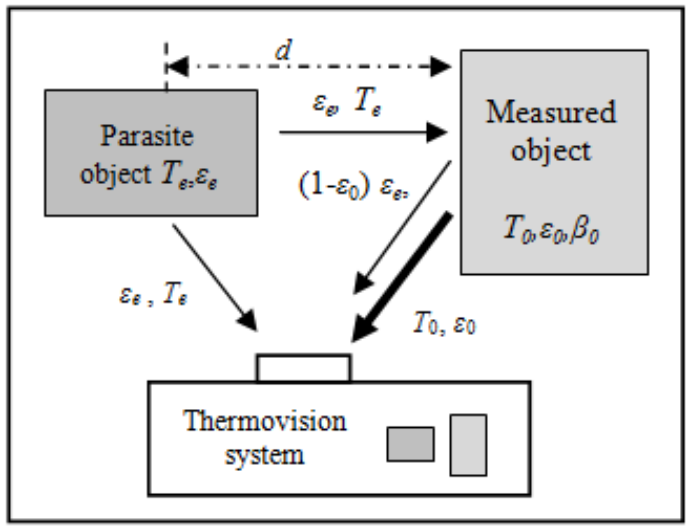

Fig. 4. Influence of other radiating objects

\section{THERMOVISION ADDITION IN DIAGNOSTICS OF POWER TRANSFORMERS}

The temperature measurement by means of contact (invasive) a method is in many cases very difficult and from working and safety reasons nearly impossible. For this reason it is necessary to aim at such measuring equipment and methods of temperature measurements which do not require the direct contact with measured equipment. Diagnostics of equipment satisfying these conditions are based on the radiated infrared energy scanning. Infrared techniques thus finds its application anywhere such physical quantity, like temperature, gives us information about the technical state of the equipment in question or about some its part.

Infrared thermograph is a contactless (noninvasive) way of temperature distribution measurement on the scanned object surface in the infrared area $(1 \mu \mathrm{m}-13 \mu \mathrm{m})$ of the electromagnetic spectrum.

Infrared measurements can be realized quickly and economically with the minimum time and work as they do not require any adaptations or turningout of measured equipment. Thermovision techniques are used at the transformers control in order to find out whether the temperature of its some parts does not raise (Fig. 5). Also the transformer's bushings, thermal field distribution on oil transformer tanks are tested, etc.

\section{THERMAL PROCESSES IN DISTRIBUTION OIL TRANSFORMER}

Electric energy lost in transformer in conversion of alternating current is converted into heat in winding, magnetic circuit and in other parts of the transformer. At the same time transformer heat's up and the temperature of its individual parts can greatly exceed the ambient temperature. With increasing load and with emerging losses the temperature of the transformer rises, this all depends on cooling winding, magnetic circuit and other heated parts.
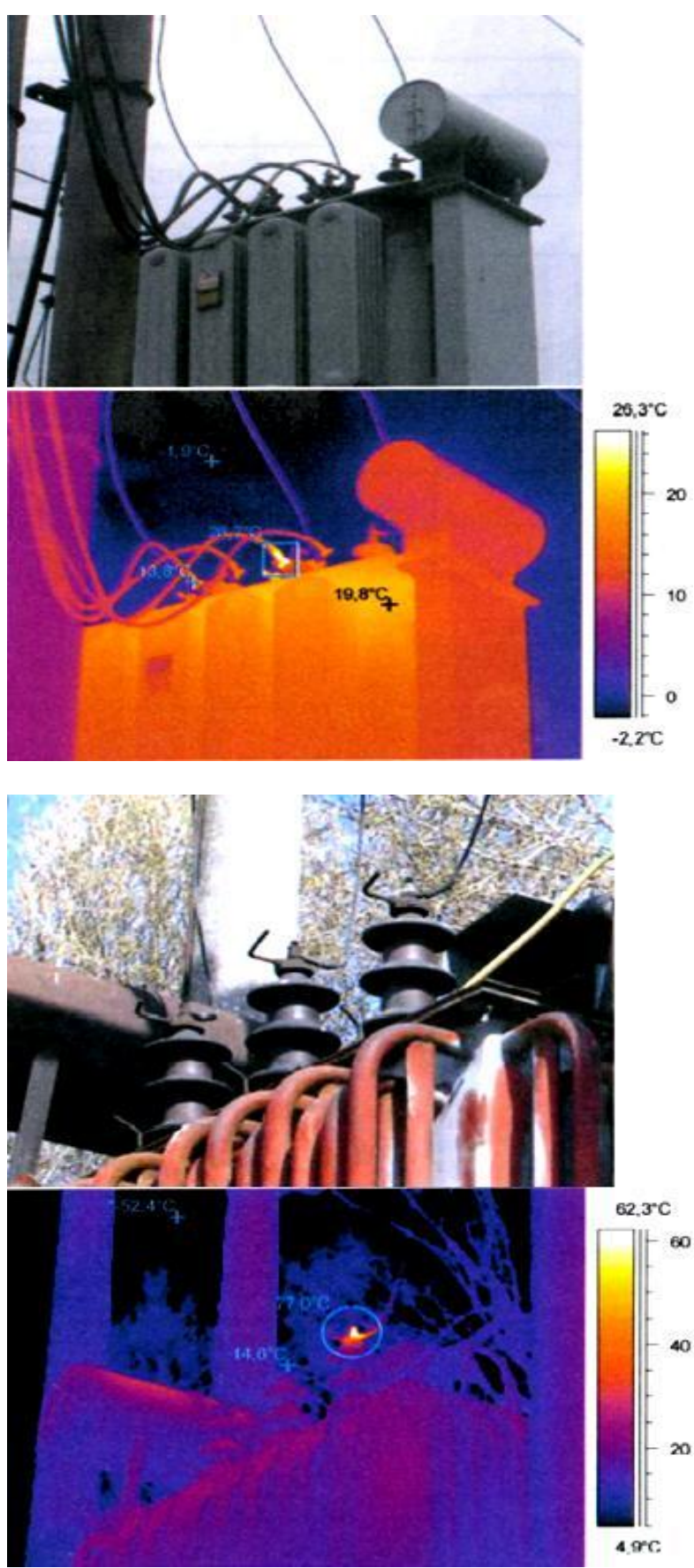

Fig. 5. Real transformer temperature picture

As far as temperature, transformer is inhomogeneous element. Sheets of magnetic circuit are characterized by high thermal conductivity and relatively low thermal capacity. They are taking turns with layers of insulation (lacquer etc.), whose thermal conductivity is not large. Similarly, the winding of the transformer is a complex configuration of copper or aluminum, which has high thermal conductivity with insulating material. It consists of electrical insulation as well as thermal insulation. 
In oil transformers, magnetic circuit and windings are sprayed by transformer oil, where the level is considerably higher than the highest part of the magnetic circuit. Oil particles (Fig. 6), tangential to the warm surface of the winding and the magnetic circuit are heated, soar upwards and transmitted it's heat through the walls and the lid of the container into the surrounding area. Cooled oil particles fall down and release their place for other warmer particles. In this case the share of heat happens by convection. Between winding and magnetic circuit on one side and oil on the other side a temperature difference is stabilized. However, the oil temperature and other parts of the transformer tank at different heights are different. Fig. 8 shows a typical waveform of temperature changes due to height of the transformer.

Heat passes through the transformer tank wall. Transfer of heat from the surface of the tank is caused by convection, i.e. by the movement of the hot moving particles as well as by radiation of heat. The temperature difference between the tank and the ambient air can reach several dozen of degrees. Typical distribution of temperatures in horizontal cut of oil transformer is shown in Fig. 6. [10]

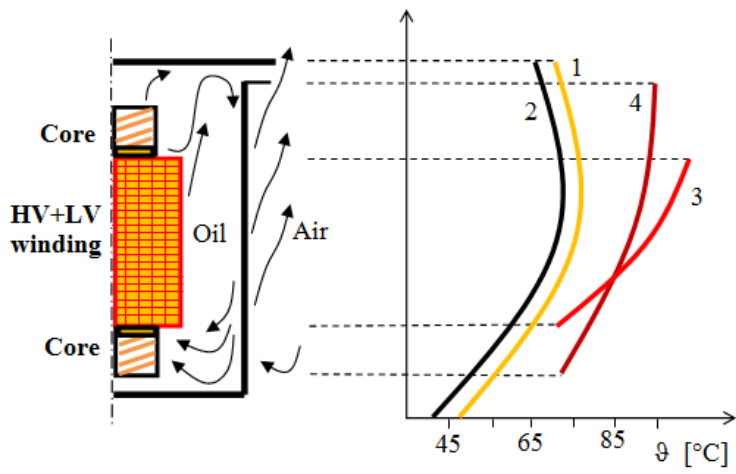

1 - oil temperature, 2 - wall of tank temperature, 3 winding temperature, 4 - core temperature

Fig. 6. Typical temperature course in dependence on height of oil transformer

\section{DESCRIPTION OF EXPERIMENTAL MEASUREMENT}

As an example of analysis of thermal processes in transformer by using the thermovision and method of monitoring refrigerating curves by optical detectors it was used experimental measurement with distribution oil transformer 30 $\mathrm{kVA}, 22 / 0.4 \mathrm{kV}$ with cooling natural system (Fig. 8 ), which is located in the Laboratory of electrical machine diagnostics of the University of Zilina.

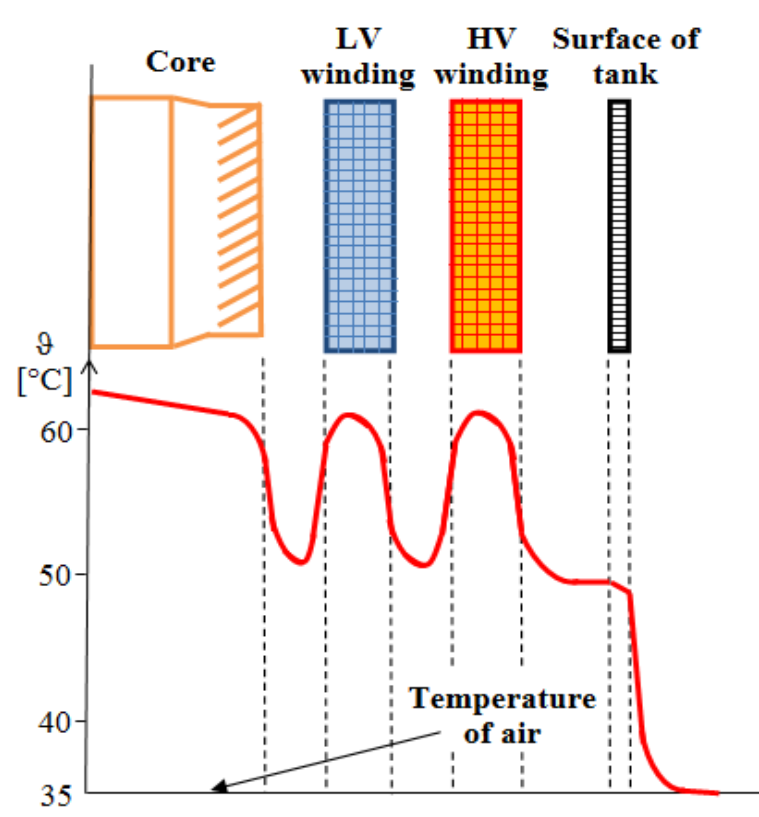

Fig.7. Typical temperature distribution in sectional plan of oil transformer

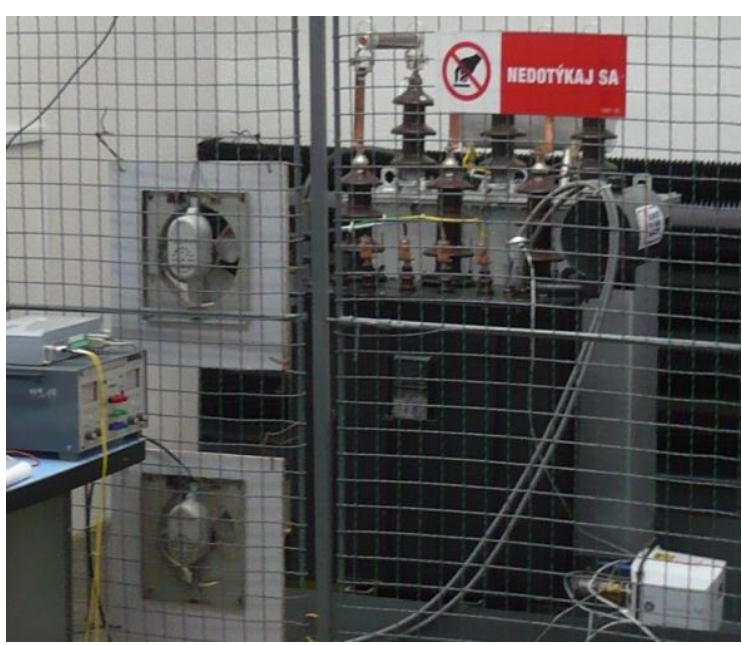

Fig. 8. View of the measured transformer and system NEOPTIX T

For contact thermal measurement of transformer winding was used two optical detectors by fibers. They were led out by special duct to the top part of the transformer tank and mounted on the middle winding at its top and middle part and from there they were led by two optical fibers to the measuring system NEOPTIX T (Fig. 8), which was analyzed measured temperature of transformer winding.

Transformer contacts, bushings and tank is monitored by thermovision camera FLUKE. In Fig. 9-down is vertical decrease of temperature for monitoring transformer winding in top (W1) and middle (W2) part of the coil. According to [11], [12] thermal strain is the greatest in the top area of the transformer. Thermal influence of core on surrounding areas of transformer (winding, oil, and tank) is simulated in Fig. 10. 
It is necessary to suggest, that according to Fig. 6 it attained temperature difference between tank and winding top of oil transformer about $50 \%$.

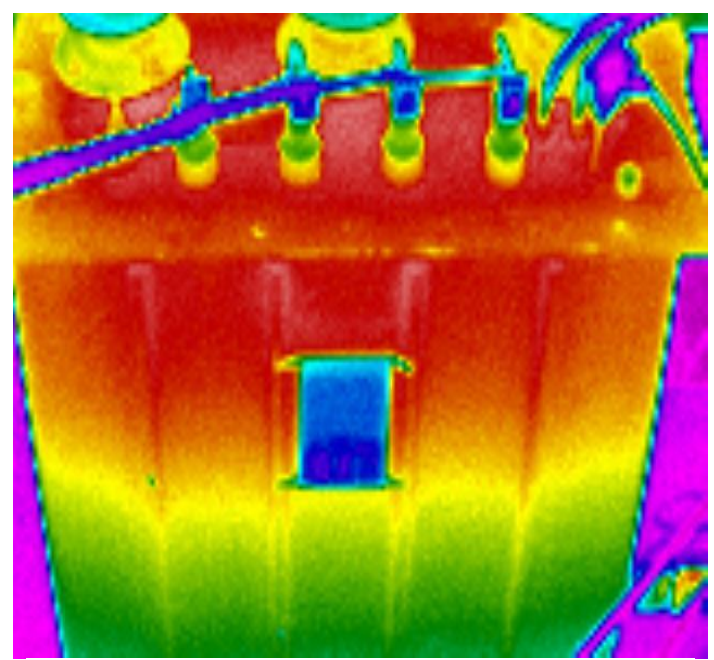

Vertical decrease of temperature

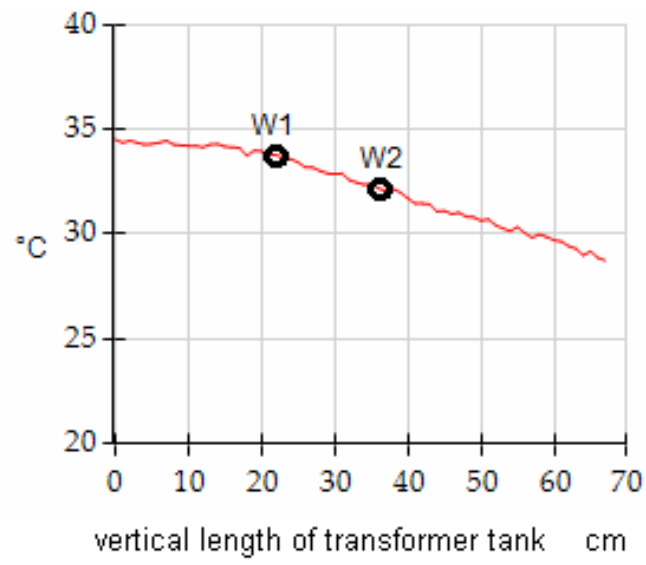

Fig. 9. Decomposition temperature of monitored transformer $22 / 0.4 \mathrm{kV}-30 \%$ load

After several months lasting operation of the transformer at approximately $30 \%$ load the analysis of measured temperature values in dependence on time at its sudden cut off was performed on measured winding phase.

It is necessary to mention that in oil tank the top and the middle part of the winding reacts differently on sudden changes. Thereby we observed possible behavior differences at two winding parts during refrigeration process after cutting the device off. Levels of refrigeration decrease may include level of winding mechanical strength, insulation quality and viscosity of oil in the transformer tank.

Fig. 11 shows the comparison of measured windings temperature values in dependency on the time after cutting the device off. The temperature decrease to $48{ }^{\circ} \mathrm{C}$ in the top part of the windings (W1) took 75 seconds and in the middle part (W2) only 50 seconds. That corresponds to the expected oil's temperature distribution after cutting the transformer off.

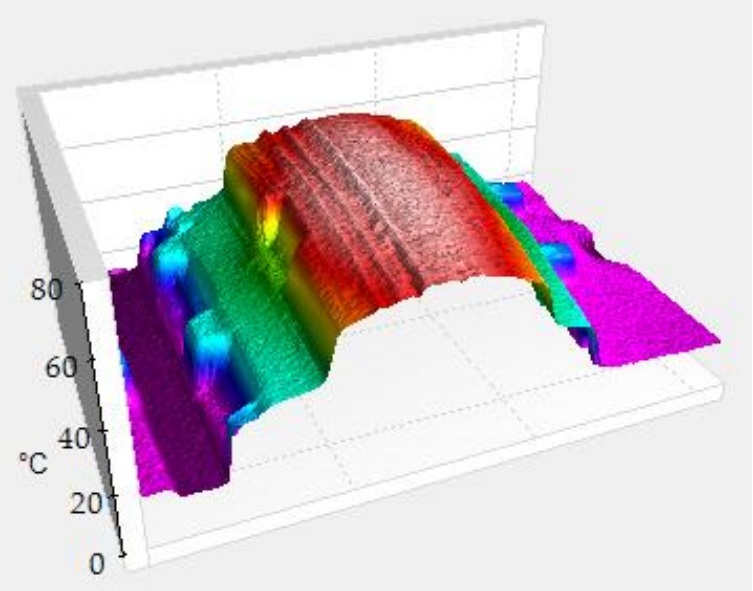

Fig. 10. Thermal influence of core on surrounding areas of distribution transformer

The temperature of oil in the transformer tank increases from certain minimum value at the bottom of the tank to the maximum value approximately to the height of the windings top edge. This maximum temperature is more or less maintained in the whole mass of oil under the top transformer cover.

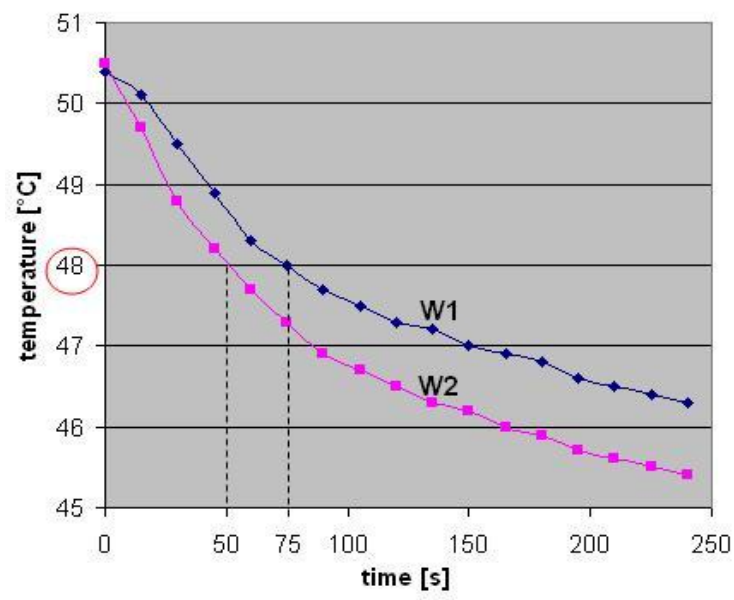

Fig. 11. Measured windings temperature values in dependency on the time

\section{DISCUSSION TO THE MEASURED DATA}

It was detected some conclusions on the base comparing the measured refrigerating curves on the top part (W1) and on the middle part (W2) of the same winding phase by optical detectors and thermovision of transformer tank.

Measured parts of windings show different dependency of refrigerating curves. It is mainly caused by the level of distribution of the oil temperature rise and the winding surface with respect to the ambient along the height of measured transformer. According Fig. 9 it is temperature difference about $2{ }^{\circ} \mathrm{C}$ between optical sensors W1 and $\mathrm{W} 2$, which was measured on surface of tank by thermovision camera.

When decreasing the selected measured temperature $\vartheta=48{ }^{\circ} \mathrm{C}$, which represents 
approximately $60 \%$ of the amount of exponential refrigerating curve, it was determined the cooling time for the W1 $t_{1}=75 \mathrm{~s}$ and for the W2 $t_{2}=50 \mathrm{~s}$ from the graph in Fig. 11.

By comparing these detected values using the equations (10) and others by [13] it was identified out on the top part of the windings (W1) until 1.5 times higher possible stress of the mechanical strength caused by temperature shocks (shortcircuit currents) than on the middle part of the windings (W2). That is also proved in the following equation:

$$
a=\frac{A_{1}}{A_{2}}=\frac{t_{1}}{t_{2}}=\frac{75}{50}=1.5
$$

where [14]

$a$ - multiple of short-circuit strength,

$A_{1}, A_{2}$ - damping coefficients at cooling process,

$t_{1}, t_{2}-$ cooling time.

It is obvious that the top part of the windings will be the most heavily stressed by the effects of temperature degradation by operation or shortcircuit currents.

\section{CONCLUSION}

A very important problem, whether in electrical engineering or other industries, is the identification of a failure, when it is still unnecessary to dismantle the equipment (diagnostics without dismantling). In this paper, we wanted to show out the possibility of using thermal measurements in this field of analysis and detection of quality of winding for distribution oil transformer.

These methods possible to localize places of faults and it can also serve for the diagnosis and detection of disorders in material quality and other anomalies during operation of the equipment [15], [16].

By the experimental measurements and following diagnostic analysis it was showed the practical use of thermovision and optical sensors for diagnostics of power oil transformers in field mechanical strength and quality of winding. It is obvious that the total mechanical degradation of coil material is given by several factors - the grade of the winding mechanical strength, the insulation quality of coil, but also the oil conductivity and viscosity in the transformer tank.

In conclusion it showed important facts, that transformers with much number of shorts it is necessary to analyze for whole interval time of the short-circuit currents, to prevent unpredictable fault during operation. It is necessary to choose the suitable diagnostics, which could anticipate such a condition.

\section{ACKNOWLEDGMENTS}

This work was supported by the Grant Agency VEGA from the Ministry of Education of Slovak Republic under contract 1/0602/17.

\section{REFERENCES}

1. Šebök M, Gutten M, Kučera M. Diagnostics of electric equipments by means of thermovision. Przeglad elektrotechniczny. 2011; 87(10): 313-317.

2. Glowacz A, Glowacz W, Glowacz Z, Kozik J, Gutten M, Korenciak D, Khan ZF, Irfan M, Carletti E. Fault diagnosis of three phase induction motor using current signal, MSAF-Ratio15 and Selected Classifiers. Archives of Metallurgy and Materials. 2017; 62(4): 2413-2419.

https://doi.org/10.1515/amm-2017-0355.

3. Glowacz A, Glowacz A, Glowacz Z. Recognition of thermal images of direct current motor with application of area perimeter vector and Bayes Classifier. Measurement Science Review. 2015; 15(3): 119-126. https://doi.org/10.1515/msr-2015$\underline{0018}$.

4. Benko I. Determination of the Infrared surface Emisivity, Budapest, 1990.

5. Toth D. Infrared System Helps with Energy Efficiency. USA, 1995.

6. Eason G, Noble B, Sneddon IN. On certain integrals of Lipschitz-Hankel type involving products of Bessel functions. Phil. Trans. Roy. Soc. London. 1955; 247: 529-551.

7. Lysenko V. Detectors for noncontact temperature measurement. Prague, 2005.

8. Simko M., Chupac M. The theoretical synthesis and design of symmetrical delay line with surface acoustic wave for oscillators with single-mode regime of oscillation. Przeglad elektrotechniczny. 2012; 88 (12A): 347-350.

9. Klabacka E. Surface modifications for Thermovision Measurement. ČVUT Praha.

10. Petrov GN. Electrical Mechines 1, Transformers. Academia Praha. 1980.

11. Jurcik J, Gutten M, Korenciak D. Analysis of transient actions influence in power transformer. Advances in Electrical and Electronic Engineering. 2011; 9 (2): 65-69. https://doi.org/10.15598/aeee.v9i2.501.

12. Mruzek M, Gajdac I, Kucera L, Barta D. Analysis of parameters influencing electric vehicle range. 2016; 134: 165-174. https://doi.org/10.1016/j.proeng.2016.01.056

13. Gutten M, Trunkvalter M. Thermal effects of shortcircuit current on winding in transformer oil. Przeglad elektrotechniczny. 2010; 86 (3): 242-246.

14. Spanik P, Sedo J, Drgona P, Frivaldski M. Real time harmonic analysis of recuperative current through utilization of digital measuring equipment. Elektronika ir Elektronika. 2013;19(5):33-38. https://doi.org/10.5755/j01.eee.19.5.4364

15. Kanuch J, Girovsky P. The device to measuring of the load angle for salient-pole synchronous machine in education laboratory. Measurement: Journal of the International Measurement Confederation. 2018; 116: 49-55. https://doi.org/10.1016/j.measurement.2017.10.043

16. Kanuch J, Girovsky P. Motor for direct drive of electric wheelchair. International Journal of 
Engineering Research in Africa. 2017; 31: 94-103. https://doi.org/10.4028/www.scientific.net/JERA.31. $\underline{94}$

Received 2019-02-11

Accepted 2019-04-25

Available online 2019-05-08

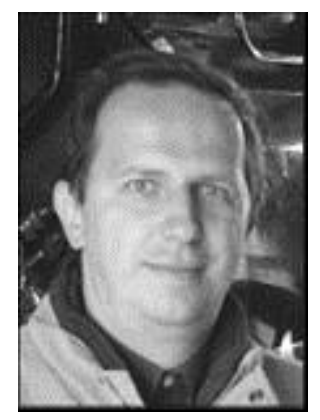

Prof. Miroslav GUTTEN,

PhD., University of Zilina participating organization in its scientific and research activities is dealing for several years with the solution of the project and grant tasks in area of diagnostics of electrical equipment (electrical machines, automotive systems, electrical transfer devices). Head of research team and Department of Measurement and Application Electrical Engineering. 